\title{
Salinização dos Solos e Práticas Agrícolas na Comunidade Quilombola de Cupira em Santa Maria da Boa Vista, Pernambuco - Nordeste do Brasil
}

\section{Salinization of soils and agricultural practices in the community of Quilombola de Cupira in Santa Maria da Boa Vista, Pernambuco - northeast Brazil}

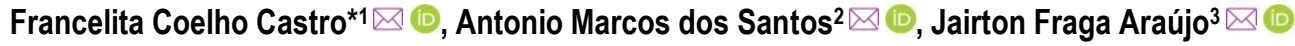 \\ 1Programa de Pós-graduação em Geografia, Universidade Federal do Ceará, Fortaleza, Ceará, \\ Brasil \\ Recebido (Received): 03/09/2020 \\ Aceito (Accepted): 06/04/2021
}

2Programa de Pós-graduação em Ciência e Tecnologia Ambiental, Universidade de

Pernambuco, Petrolina, Pernambuco, Brasil

3Departamento de Tecnologia e Ciências Sociais, Universidade do Estado da Bahia, Juazeiro,

Bahia, Brasil

E-mail: geo_fisica@yahoo.com.br (AMS); jairtonfraga@bol.com.br (JFA)

*E-mail para correspondência: francelitacastro@gmail.com

Resumo: O processo de salinização dos solos é definido como o acúmulo de íons solúveis nas camadas agricultáveis acarretando perda de fertilidade e produtividade, sendo responsável pela degradação de milhares de hectares de solos nas regiões secas do ecúmeno terrestre, proporcionando perdas econômicas e socioambientais. O presente artigo tem como objetivo analisar a relação entre o manejo adotado na comunidade Quilombola de Cupira (Pernambuco - Brasil) com o processo de salinização dos solos locais. Para realização deste estudo foram aplicados 14 formulários direcionados a agricultores com intuito de coletar informações sobre as práticas agrícolas adotadas. Além disso, foram coletadas amostras de solos em cada propriedade dos entrevistados para realização de análises químicas para aferição da presença de sais. Os resultados indicam que $71,42 \%$ das amostras apresentam problemas de salinização, sendo 57,14\% classificadas como solos salino-sódicos, 7,14\% sódicos, 7,14\% salinos e 28,57\% normais. Os fatores que se destacam como incisivos no processo de salinização das terras analisadas são: as práticas de irrigação; uso de fertilizantes e pesticidas; e a falta de orientações quanto ao manejo adequado às características dos solos locais. O manejo aplicado na comunidade Quilombola de Cupira vem auxiliando no desenvolvimento do processo de salinização dos solos, sendo consequência da falta de políticas públicas de apoio ao agricultor.

Palavras-chave: Semiárido; Agricultura irrigada; Manejo; Acúmulo de sais; Solos salinos.

Abstract: The process of salinization of soils is defined as the accumulation of soluble ions in the agricultural layers causing loss of soil fertility and productivity, being responsible for the degradation of thousands of hectares of soil in the dry regions of the terrestrial ecumene, providing economic and socioenvironmental losses. This article aims to analyze the relationship between the management adopted in the Quilombola de Cupira community (Pernambuco - Brazil) and the process of salinization of local soils. In order to carry out this study, 14 forms were applied to farmers in order to collect information on the agricultural practices adopted. In addition, soil samples were collected in each property of the interviewees to carry out chemical analyzes to assess the presence of salts. The results indicate that $71.42 \%$ of the properties have salinization problems, $57.14 \%$ of which are classified as sodium saline soils, $7.14 \%$ sodium, $7.14 \%$ saline and $28.57 \%$ normal. The factors that stand out as incisive in the process of salinization of the analyzed lands are: irrigation practices; use of fertilizers and pesticides and the lack of guidance on the proper management of local soil characteristics. The management developed in the Quilombola de Cupira community has been helping to develop the process of salinization of soils, resulting from the lack of public policies to support farmers.

Keywords: Semiarid; Irrigated agriculture; Management; Salt accumulation; Saline soils. 


\section{Introdução}

O processo de salinização dos solos é resultante de características ambientais e/ou ações antrópicas (VASCONCELOS, 2014; GONÇALVES; MARTINS; RAMOS, 2015; DALIAKOPOULOS et al., 2016), sendo definido como o acúmulo de íons solúveis nas camadas agricultáveis acarretando perda de fertilidade e produtividade dos solos, principalmente em regiões áridas e semiáridas (PAN et al., 2013; GKIOUGKIS et al., 2015; PEDROTTI et al., 2015; PENG et al., 2016; CASTRO; ARAÚJO; SANTOS, 2019).

Nesse sentido, os manejos inadequados podem favorecer o desenvolvimento ou o agravamento do processo de salinização (SILVA; SILVA, 2015), como o uso indiscriminado de fertilizantes (DALIAKOPOULOS et al., 2016), a utilização de água contendo valores elevados de sais (RAJPUT et al., 2016; FENG et al., 2017) e a aplicação de excesso de água e/ou sem sistema de drenagem (RAJPUT et al., 2016).

A aplicação de adubos químicos nitrogenados em áreas de produção agrícola em quantidade acima do necessário afeta negativamente o crescimento das plantas, e contribui para o desenvolvimento do processo de salinização dos solos (SHEN et al., 2016; CHU et al., 2017). Outra causa comum da salinização é o uso inadequado de produtos químicos na fertirrigação, ocorrendo o acúmulo de íons, como os cátions $\mathrm{Na}^{+}, \mathrm{Ca}^{2+} \mathrm{e}$ $\mathrm{Mg}^{2+}$ que tem como consequência problemas na absorção de água pelas plantas (SILVA et al., 2013; SILVA, 2014).

A utilização da água com teores elevados de sais nas áreas de agricultura irrigada é uma das práticas de manejo que pode acarretar, em longo prazo, o acúmulo de sais nos solos (FENG et al., 2017). A água a ser utilizada na agricultura irrigada deve ser analisada antes do início da aplicação no cultivo, pois a água com altos teores de sais é um dos fatores que influencia negativamente na produção agrícola irrigada nas regiões secas do mundo (MEDEIROS; NASCIMENTO; GHEYI, 2010).

A prática da agricultura irrigada tem adicionado ao solo mais água do que o necessário em áreas irrigadas, além de apresentar, na maioria dos países em desenvolvimento, sistemas de drenagem com deficiência por falta de manutenção ou que, de fato, não são implementados (RESENDE et al., 2014).

A agricultura irrigada, no Brasil, também é praticada por comunidades tradicionais, como é a comunidade indígena Truká, localizada na Ilha de Assunção, no município de Cabrobó, estado de Pernambuco. As práticas agrícolas adotadas pelos agricultores dessa comunidade contam com aplicação de insumos, com cultivos e práticas agrícolas inadequadas para as características do solo da região, causando perda de produtividade e da fertilidade, e salinização dos solos, seguida de abandono da área degradada para exploração em outra área do território tradicional (SILVA; SILVA, 2015).

Diante do apresentado, analisar a relação das práticas de manejo dessas comunidades tradicionais com as áreas de acúmulo de sais torna-se imprescindível para o processo de tomada de decisões e direcionamento de manejos sustentáveis para essas áreas. Vale destacar, também, que apesar da salinização dos solos ser um problema presente na região do Vale do São Francisco, seus estudos em áreas de comunidades tradicionais e de pequenos agricultores são reduzidos e não focam na relação do manejo com o processo de salinização. Neste contexto, o objetivo desse artigo é analisar a relação entre o manejo agrícola adotado na comunidade Quilombola de Cupira com os possíveis focos de salinização dos solos locais.

\section{Materiais e métodos}

\subsection{Localização e caracterização da área de estudo}

A comunidade quilombola de Cupira está localizada à cerca de $14 \mathrm{~km}$ da cidade de Santa Maria da Boa Vista, semiárido do estado de Pernambuco (Figura 1), nas margens do Rio São Francisco, entre as coordenadas de $8^{\circ} 43^{\prime} 28^{\prime \prime}$ e $8^{\circ} 47^{\prime} 57^{\prime \prime}$ de latitude sul e $39^{\circ} 41^{\prime} 59^{\prime \prime}$ e $39^{\circ} 45^{\prime} 28^{\prime \prime}$ de longitude oeste. A comunidade foi reconhecida como comunidade quilombola em 2008 pela Fundação Cultural Palmares.

A história da comunidade está escrita nos registros da Associação Quilombola dos Agricultores Familiares e Pescadores do Território de Cupira (AQAFPTC). Segundo informações da AQAFPTC, a comunidade era denominada de Estreito, devido à pequena extensão de terra entre a serra e o Rio São Francisco. O nome de Cupira surgiu posteriormente, por causa da marcante presença de seu Manoel Cupira, pescador do Rio São Francisco e que coletava mel da abelha cupira, motivo pelo qual recebeu o nome e deixou registrado na história da comunidade. Com cerca de 220 famílias, a comunidade possui como principais atividades a agricultura irrigada, o artesanato e a pesca, todas realizadas em regime familiar. 


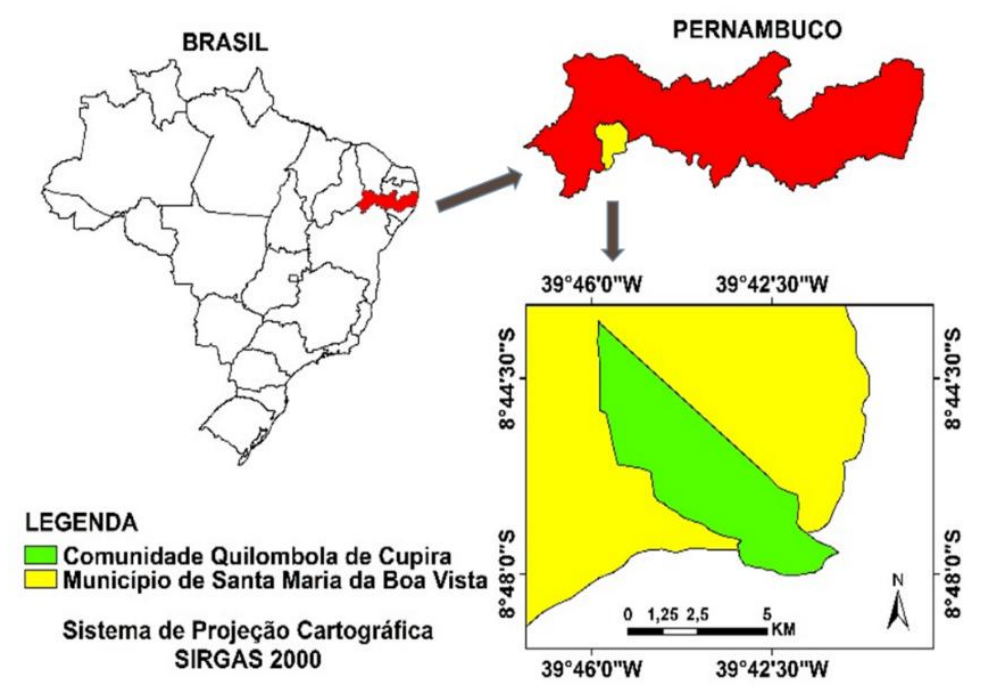

Figura 1: Localização da comunidade quilombola de Cupira - Santa Maria da Boa Vista - Pernambuco. Fonte: autores, (2019).

O município de Santa Maria da Boa Vista, no qual está inserido a comunidade, possui 39.435 habitantes, com densidade demográfica de 13,14hab/ $\mathrm{km}^{2}$ (IBGE, 2017). O clima é o Tropical Semiárido, com temperaturas médias de $28^{\circ} \mathrm{C}$, período de chuva entre novembro e abril e com média pluviométrica anual de 431,8mm (BELTRÃO et al., 2005).

De acordo com Castro; Araújo; Santos, (2019) a área de abrangência da comunidade apresenta as seguintes classes de solos: Planossolo Nátrico Órtico Arênico; Gleissolo Háplico Tb Eutrófico Neofluvissólico; Neossolos Flúvicos Tb Eutrófico Típico; e Neossolo Litólico Eutrófico Fragmentário e uma estrutura geológica com quatro diferentes classes, sendo elas: Complexos granito-gnaisse-migmátitos; Complexos granitóides muito deformados; Sequência Vulcano-sedimentares e Depósitos aluvionares recentes.

\subsection{Procedimentos metodológicos}

Para realização do presente trabalho foram necessárias duas etapas, uma em campo e outra em laboratório. Em campo, foram entrevistados 14 agricultores com auxílio de formulários semiestruturados com solicitação de informações referentes ao sistema de irrigação, manejo de adubação e tipos de cultivo. Para a escolha dos entrevistados, foi realizado um encontro com os representantes da comunidade, no qual foi explicado que as entrevistas seriam feitas com os agricultores mais experientes no manejo do solo e no plantio. As indicações dos entrevistados foram realizadas pelos representantes presentes na reunião.

Quanto aos aspectos éticos e legais da pesquisa, o projeto foi aprovado pelo comitê de ética da Universidade do Estado da Bahia, parecer 2.007.840. Foram esclarecidas dúvidas aos participantes da pesquisa, sobre o projeto e o uso das informações que seriam coletadas. Todos assinaram o TCLE (Termo de Consentimento Livre e Esclarecido).

Em seguida, cada agricultor foi direcionado a sua área de plantio, onde foi entrevistado e solicitado a indicar quais locais apresentavam problemas de salinização. No local apontado em cada propriedade, foram abertas 4 trincheiras de $30 \mathrm{~cm}$ de profundidade, sendo coletadas amostras de solos, as quais foram misturadas em sacolas plásticas, indicando assim, a representatividade da localidade amostral - método baseado no Manual de procedimentos de coleta de amostras em áreas agrícolas para análise da qualidade ambiental: solo, água e sedimentos, desenvolvido por Filizola; Gomes; Souza, (2006). Ao todo foram visitadas 14 propriedades.

A coleta das amostras de solo foi realizada entre os dias 10 de maio a 10 de julho de 2017, período que corresponde ao inverno com baixíssimos índices pluviométricos na área de estudo. Isso evitou qualquer interferência das precipitações pluviométricas sobre a lavagem ou qualquer outra interferência nos solos.

De posse dos dados de campo, os mesmos foram processados em laboratório, constituindo assim, a segunda etapa de estudo. Todas as amostras de solos foram submetidas a análises químicas, sendo realizados testes de pH (potencial Hidrogeniônico), CE (Condutividade Elétrica), RAS (Relação de Adsorção de Sódio) 
e PST (Porcentagem de Sódio Trocável). Todo procedimento laboratorial foi baseado no Manual de Métodos de Análise de Solos (EMBRAPA, 2011).

O potencial Hidrogeniônico "é uma medida que permite descrever o caráter ácido ou básico que predomina em meio aquoso, tendo em conta o seu valor determinado numa escala de zero a 14" (LEPSCH, 2011, p.210 e 211). O pH tem seu caráter definido de acordo com as concentrações de hidrogênio $\left(\mathrm{H}^{+}\right)$e de hidroxila $\left(\mathrm{OH}^{-}\right)$: com predominância dos íons de $\mathrm{H}^{+}$sobre os íons de $\mathrm{OH}^{-}$o caráter é ácido; em caso contrário, alcalino. Quando ocorrem situações de concentrações equivalentes de íons, as reações são ditas neutras (QUEIROZ et al., 2010).

A condutividade elétrica é reflexo da mudança no conteúdo de água e/ou diluição da solução no solo, expressando a habilidade do meio em conduzir corrente elétrica (RICHARDS, 1954; QUEIROZ et al., 2010). O PST é a porcentagem que o sódio representa em relação aos cátions adsorvidos no solo (QUEIROZ et al., 2010) e o RAS expressa o equilíbrio de cátions monovalentes de sódio ( $\mathrm{Na}$ ) com divalentes de cálcio e magnésio (Ca e Mg) (MATOS; ALMEIDA NETO; MATOS, 2014). Exames que, segundo a USSL Staff (1954) e Ribeiro (2010), são essenciais para avaliação da salinidade dos solos.

Os cálculos do PST e da RAS foram obtidos através das equações 1 e 2, respectivamente.

$$
\begin{array}{r}
P S T=\left(\frac{N a^{+}}{C T C}\right) 100 \\
R A S=\frac{N a^{+}}{\sqrt{\frac{C a^{++}+M g^{++}}{2}}}
\end{array}
$$

Em que: CTC é a capacidade de troca de cátion em $\mathrm{cmol}_{\mathrm{c}} \mathrm{Kg}^{-1}$ obtida através da soma das bases $\left(\mathrm{Ca}^{2+}\right.$ Cálcio; $\mathrm{Mg}^{2+}$ - Magnésio; $\mathrm{K}^{+}$- Potássio; $\mathrm{Na}^{+}$- Sódio; $\mathrm{H}$ - Al - Alumínio trocável).

Os resultados das análises químicas foram classificados a partir da metodologia de Bohn; McNeal; O'Connor, (1985) conforme a Tabela 1. Em casos que as amostras analisadas não se enquadrassem nos critérios da tabela 1 foi levado em consideração o papel da CE como determinante no processo de salinização dos solos. Critério baseado nos estudos Aguiar Netto et al., (2007) e Ribeiro, (2010).

Tabela 1: Critérios para classificação dos solos quanto à presença de sais.

\begin{tabular}{cccc}
\hline Classificação dos solos & & Limite dos parâmetros & \\
& $\mathbf{p H}$ & $\mathbf{C E}\left(\mathbf{d} \mathbf{~ m}^{-\mathbf{1}}\right)$ & PST \\
\hline Normais & $<8,5$ & $<2$ & $<15$ \\
Salinos & $<8,5$ & $>2$ & $<15$ \\
Sódicos & $>8,5$ & $<2$ & $>15$ \\
Salinos-sódicos & $<8,5$ & $>2$ & $>15$ \\
\hline
\end{tabular}

Fonte: Bohn; McNeal; O’Connor, (1985).

\section{Resultados e discussões}

A Figura 2 apresenta a classificação geral das amostras de solo de cada propriedade agrícola visitada quanto à presença de sais de acordo com as análises físico-químicas de $\mathrm{pH}, \mathrm{CE}$, PST e RAS, enquanto que a tabela 2 demonstra as análises químicas individuais por amostra, as quais são classificadas como: sódicas; salinas-sódicas; salinas e normais, segundo Bohn; McNeal; O’Connor, (1985) (Tabela 1).

Os resultados apontam que a maior parte das amostras, $57,14 \%$, foram classificadas como salinas-sódicas, $7,14 \%$ como salinas, $7,14 \%$ como sódica e $28,57 \%$ normais (Figura 2). Segundo Ferreira; Silva; Ruiz, (2010), as amostras consideradas salinas-sódicas são caracterizadas pela presença de sais em solução com quantidades que causam estresse osmótico às plantas, sendo a relação de sódio trocável bastante elevada. Quanto aos solos salinos, estes possuem valores elevados de sais em solução e são geralmente floculados, apresentando permeabilidade igual ou maior aos solos similares não salinos (FERREIRA; SILVA; RUIZ, 2010; RIBEIRO, 2010). 


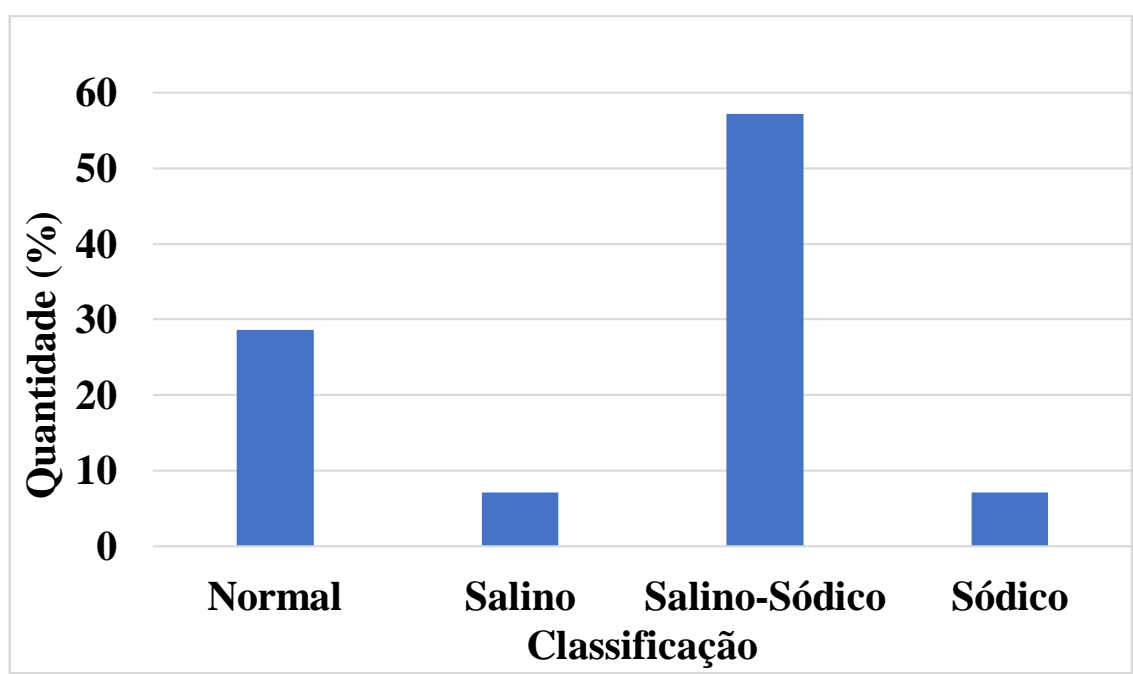

Figura 2: Classificação das amostras de solos de cada propriedade agrícola quanto à presença de sais. Fonte: autores, (2019).

Tabela 2: Classificação das amostras de solos de cada propriedade agrícola quanto à presença de sais.

\begin{tabular}{cccccc}
\hline $\begin{array}{c}\text { Propriedades/ } \\
\text { Amostras }\end{array}$ & $\mathbf{p H}$ & $\mathbf{C E}$ & $\mathbf{P S T}$ & $\mathbf{R A S}$ & $\begin{array}{c}\text { Classificação } \\
\text { das amostras }\end{array}$ \\
\hline $\mathbf{1}$ & 6,46 & 6,81 & 49,08 & 6,52 & Salino-sódico \\
$\mathbf{2}$ & 6,64 & 58,64 & 1,50 & 0,13 & Salino \\
$\mathbf{3}$ & 6,32 & 1,07 & 2,47 & 0,15 & Normal \\
$\mathbf{4}$ & 6,67 & 0,9 & 0,36 & 0,02 & Normal \\
$\mathbf{5}$ & 5,79 & 8,29 & 35,73 & 3,75 & Salino-sódico \\
$\mathbf{6}$ & 4,9 & 3,89 & 25,10 & 2,16 & Salino-sódico \\
$\mathbf{7}$ & 5,88 & 3,69 & 35,77 & 3,55 & Salino-sódico \\
$\mathbf{8}$ & 6,06 & 1,1 & 22,71 & 2,02 & Sódico \\
$\mathbf{9}$ & 5,22 & 29,84 & 58,24 & 11,66 & Salino-sódico \\
$\mathbf{1 0}$ & 5,88 & 0,87 & 1,80 & 0,12 & Normal \\
$\mathbf{1 1}$ & 5,36 & 0,47 & 0,75 & 0,04 & Normal \\
$\mathbf{1 2}$ & 6,76 & 3,02 & 17,97 & 1,61 & Salino-sódico \\
$\mathbf{1 3}$ & 4,47 & 4,37 & 53,14 & 7,95 & Salino-sódico \\
$\mathbf{1 4}$ & 6,31 & 11,43 & 22,20 & 2,38 & Salino-sódico \\
\hline
\end{tabular}

Fonte: autores, (2019).

Resultados semelhantes aos encontrados nesta pesquisa foram verificados por Vasconcelos et al., (2013) em lotes do Perímetro Irrigado de Ibimirim, Pernambuco e por Freire et al., (2014) no Perímetro Irrigado de Custódia, localizado no município de Custódia, também no estado de Pernambuco. No Ceará, estudo de Moreira; Teixeira; Galvão, (2014) no distrito de irrigação Morada Nova, foram encontradas áreas degradadas pelo processo de acúmulo de sais causado pelo histórico do manejo de exploração dos solos com aplicação de água em excesso.

Já os solos sódicos são, de acordo com Ferreira; Silva; Ruiz, (2010) e Ribeiro (2010), materiais com sódio trocável e pH elevados, resultando em dispersão das partículas de argila e matéria orgânica, acarretando cores escuras aos solos e dificuldades de penetração de água e raízes. No caso em análise, a propriedade no qual foi classificada com solo sódico não apresenta um $\mathrm{pH}$ acima de 8,5 (Tabela 2) mas apresentou as demais características de solo sódico como PST elevado e apresentou uma CE baixa não atendendo a características para a classe salino-sódica.

Em 8 propriedades, nas quais as amostras foram classificadas com problemas de salinização, a irrigação vem sendo desenvolvida através de sulco (Figura 6A) e, nas demais amostras, o sistema utilizado é o de microaspersão (Figura 6B). No entanto, tais áreas já foram irrigadas por sulco, anteriormente. Testezlaf (2017) chama à atenção para algumas desvantagens do sistema de irrigação por sulco: segundo o pesquisador, há acúmulo de sais no solo devido à maior quantidade de água introduzida e, consequentemente, um maior tempo de permanência da mesma. 

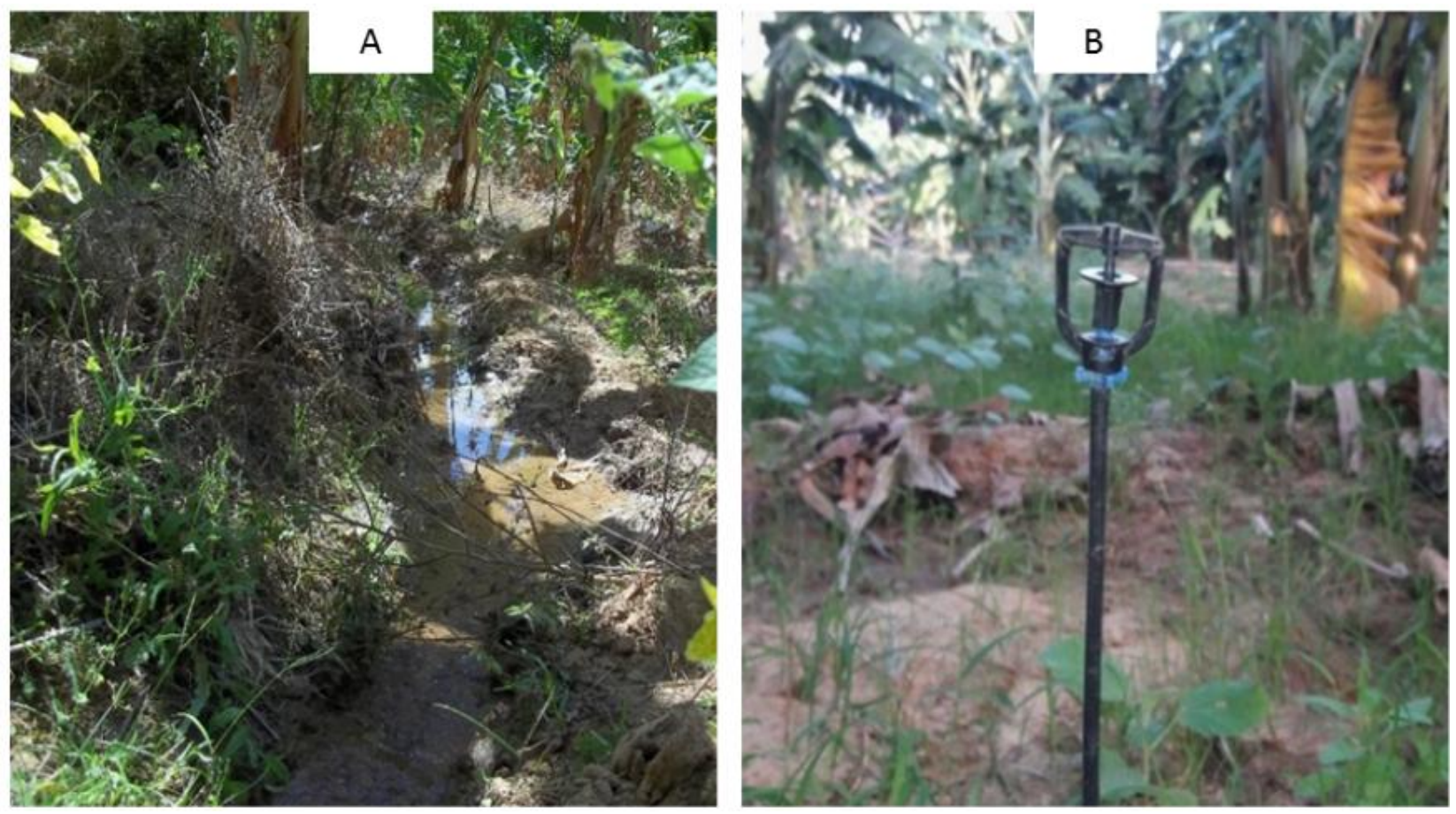

Figura 6: (A) irrigação através de sulcos e (B) irrigação por microaspersão. Fonte: autores, (2018).

O sistema de irrigação por microaspersão apresenta vantagens, como facilidade de adaptação às diversas condições do solo, cultivos e topografia, e maior eficiência potencial que o método de superfície (EMBRAPA, 2001). Pelo reconhecimento a essas vantagens, os agricultores que possuem viabilidade financeira estão implantando esse sistema nas suas áreas de produção.

Em relação ao tempo e à quantidade de água aplicada na irrigação, em todas as propriedades, os agricultores entrevistados não realizam cálculo para determinação da quantidade de água a ser aplicada nas áreas de cultivo, por falta de assistência técnica, o que é justificado pelas condições financeiras dos agricultores e falta de apoio do poder público. De acordo com Mota et al., (2012), a salinização dos solos na região semiárida tem sido provocada tanto pelo sistema de irrigação inadequado, a exemplo dos sulcos, como também pelo modo como essa prática está sendo executada. Um dos exemplos é a ausência de cálculos por parte de muitos agricultores quanto à proporção quantidade/tempo de adicionamento da água na atividade agrícola.

Entretanto, a falta de sistema de drenagem acarreta preocupações para a comunidade. Pelos relatos dos agricultores, foi construído um sistema de drenagem pela CODEVASF (Companhia de Desenvolvimento dos Vales do São Francisco e do Parnaíba), que não atendeu a todo o território da comunidade. Posteriormente, não foram realizadas manutenções (Figura 7). Relata-se, ainda, que algumas áreas que não produziam mais, por possuírem elevadas quantidades de sais, voltaram a produzir na época da implantação dos drenos. Isso ocorreu por que o sistema de drenagem contribuiu para a retirada dos sais, diminuindo o grau de salinização.

A falta de utilização de sistema de drenagem já ocasionou problemas de salinização em vários perímetros irrigados no semiárido brasileiro, deixando os solos salinos e salinos-sódicos. Entre os perímetros que apresentaram os citados problemas estão: Sumé-Paraíba; Vaza Barris-Bahia; Jucurice-Bahia e São GonçaloParaíba. A implantação de sistemas de drenagem em regiões de clima árido ou semiárido tem como objetivos a manutenção do reservatório do aquífero em profundidades suficientes para controle da quantidade ideal de sais na zona radicular das plantas; e a eliminação do excesso de água aplicada pelo sistema de irrigação, pela chuva ou pelas lâminas de lixiviação (LIMA; FARIAS; JÚNIOR BORGES, 2010; FEITOSA et al., 2018; FREIRE et al., 2020).

Com base nos relatos, verificou-se que os agricultores cultivam banana (Musa spp.), maracujá (Passiflora edulis Sims), mandioca (Manihot esculenta Crantz), manga (Mangifera indica L.), acerola (Malpighia punicifolia L.), mamão (Carica papaya L.), milho (Zea mays L.) entre outros (Tabela 3) e deixam claro que a escolha do tipo de irrigação, assim como, o tempo de funcionamento do sistema não é estruturado a partir do tipo de cultivo. 


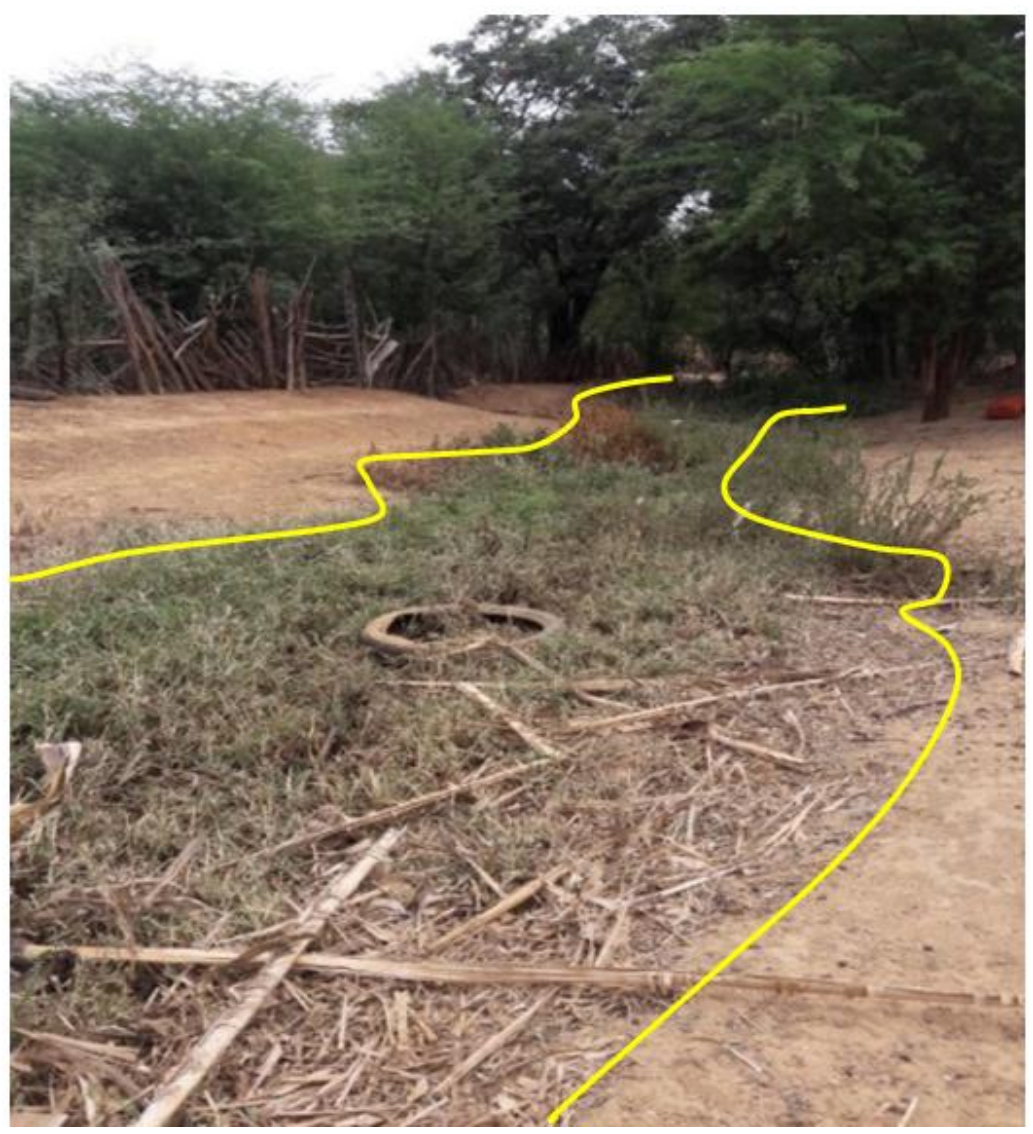

Figura 7: Dreno construído pela CODEVASF e atualmente sem manutenção. Fonte: autores, (2018).

Quanto à adubação (Tabela 3), apenas uma propriedade utiliza recursos orgânicos há mais de 10 anos, embora essa propriedade faça uso de produtos químicos para combater doenças e pragas. As demais propriedades utilizam adubação química como o sulfato de amônia $\left(\left(\mathrm{NH}_{4}\right)_{2} \mathrm{SO}_{4}\right)$, o cloreto $\left(\mathrm{Cl}^{-}\right)$, a ureia $\left(\mathrm{CH}_{4} \mathrm{~N}_{2} \mathrm{O}\right)$, o nitrato de cálcio $\left(\mathrm{Ca}\left(\mathrm{NO}_{3}\right)_{2}\right)$ dentre outros e pesticidas a exemplo do Furadan $\left(\mathrm{C}_{12} \mathrm{H}_{15} \mathrm{NO}_{3}\right)$, no combate a pragas. $\mathrm{O}$ uso da adubação química, associado a pesticidas, segundo Gonçalves; Martins; Ramos, (2015), está entre as principais ações antrópicas que resultam no acréscimo de sais nos solos.

Rodríguez-Liébana; Mingorange; Peña, (2018) destacam que os pesticidas estão mais seguros, porém a polaridade os faz mais móveis e mais facilmente transportados para as camadas profundas dos solos, causando a contaminação das águas subterrâneas e, consequentemente, ampliando a concentração de sais nos solos.

Os manejos das terras em 12 das propriedades são realizados de acordo com os conhecimentos passados para os agricultores pelas gerações anteriores e, em apenas duas propriedades, responderam ter recebido assistência técnica (Tabela 3). No entanto, essas orientações foram realizadas por pessoas que não possuem acesso a informações técnicas sobre a área de produção dos agricultores, sendo eles apenas vendedores de lojas de produtos agrícolas. De acordo com Silva; Silva (2015), os modelos de agricultura sem planejamentos e gerenciamentos adequados resultam em interferências negativas no meio ambiente.

Outro fator levantado foi o histórico de cultivo da área de estudo (Tabela 3): 7 das propriedades são cultivadas há mais de 40 anos, sendo que, por décadas, o cultivo predominante foi o arroz por inundação. Segundo Marrenjo et al., (2016), o cultivo de arroz inundado é tipicamente desenvolvido em planícies de inundação fluvial e, portanto, em solos marcados pela anaerobiose, como os Gleissolos, os Planossolos e os Neossolos Flúvicos, presentes nas propriedades da comunidade quilombola de Cupira, segundo Castro; Araújo; Santos, (2019). Com isso, os riscos e o processo de salinização na comunidade foram ampliados. 
Tabela 3: Manejo, tipos e tempo de cultivo das amostras de solos das propriedades agrícolas. Fonte: Autores (2019).

\begin{tabular}{|c|c|c|c|c|c|c|c|c|c|}
\hline \multirow{2}{*}{$\begin{array}{l}\text { Propriedades/ } \\
\text { Amostras }\end{array}$} & \multicolumn{2}{|r|}{ Irrigação } & \multicolumn{2}{|c|}{ Adubação } & \multicolumn{2}{|c|}{ O manejo é baseado em: } & \multicolumn{2}{|c|}{$\underline{\text { Tipos de Cultivo }}$} & \multirow{2}{*}{$\begin{array}{c}\text { Tempo de } \\
\text { Cultivo (anos) }\end{array}$} \\
\hline & Sulco & Microaspersão & Química & Orgânica & $\begin{array}{l}\text { Assistência } \\
\text { Técnica }\end{array}$ & $\begin{array}{l}\text { Gerações } \\
\text { passadas }\end{array}$ & Cultivos atuais & Cultivos anteriores & \\
\hline 1 & $\mathrm{X}$ & & $\mathrm{X}$ & & & $\mathrm{X}$ & Banana; & Feijão; Mandioca e Maracujá. & $>40$ \\
\hline 2 & $\mathrm{X}$ & & $\mathrm{X}$ & & & $\mathrm{X}$ & Banana; & Cebola; Melancia e Arroz. & $30-40$ \\
\hline 3 & $\mathrm{X}$ & & $\mathrm{X}$ & & & $\mathrm{X}$ & Maracujá; & Feijão; Mandioca; Cebola. & $>40$ \\
\hline 4 & & $\mathrm{X}$ & $\mathrm{X}$ & & & $\mathrm{X}$ & $\begin{array}{c}\text { Banana; coco; Manga; } \\
\text { Acerola; Uva; Mamão; } \\
\text { Maracujá. }\end{array}$ & $\begin{array}{c}\text { Cebola; Melancia; Melão; Tomate; } \\
\text { Arroz. }\end{array}$ & $<10$ \\
\hline 5 & $\mathrm{X}$ & & $\mathrm{X}$ & & & $\mathrm{X}$ & Banana e Mandioca. & $\begin{array}{l}\text { Arroz; Cebola; Maracujá e } \\
\text { Pimentinha. }\end{array}$ & $>40$ \\
\hline 6 & $\mathrm{X}$ & & $\mathrm{X}$ & & & $\mathrm{X}$ & Cana e Milho. & Cana e Milho. & $>40$ \\
\hline 7 & & $\mathrm{X}$ & $\mathrm{X}$ & & & $\mathrm{X}$ & Banana e Limão. & Melão; Cebola e Tomate. & $11-20$ \\
\hline 8 & $\mathrm{X}$ & & $\mathrm{X}$ & & & $\mathrm{X}$ & Banana. & Banana; Melão; Cebola e Arroz. & $>40$ \\
\hline 9 & & $\mathrm{X}$ & $\mathrm{X}$ & & & $\mathrm{X}$ & Maracujá e Goiaba; & $\begin{array}{l}\text { Arroz; Cebola; Melão; Tomate e } \\
\text { Mandioca. }\end{array}$ & $>40$ \\
\hline 10 & & $\mathrm{X}$ & $\mathrm{X}$ & $\mathrm{X}$ & $\mathrm{X}$ & & $\begin{array}{l}\text { Goiaba. } \\
\text { Banana; Feijão; }\end{array}$ & Cebola e Melão. & $11-20$ \\
\hline 11 & & $\mathrm{x}$ & $\mathrm{x}$ & & & $\mathrm{X}$ & $\begin{array}{l}\text { Abobora; Pimentinha e } \\
\text { Mandioca. }\end{array}$ & Arroz. & $>40$ \\
\hline 12 & $\mathrm{X}$ & & $\mathrm{X}$ & & & $\mathrm{X}$ & Banana. & Banana; Maracujá e Goiaba. & $11-20$ \\
\hline 13 & & $\mathrm{X}$ & $\mathrm{X}$ & & $\mathrm{X}$ & & $\begin{array}{l}\text { Banana; Milho e } \\
\text { Capim Correntinha. }\end{array}$ & $\begin{array}{c}\text { Capim de corte; Cebola; Feijão; } \\
\text { Melancia e Melão. }\end{array}$ & $11-20$ \\
\hline 14 & $\mathrm{X}$ & & $\mathrm{X}$ & & & $\mathrm{X}$ & Banana e Maracujá. & Goiaba e Arroz. & $21-30$ \\
\hline
\end{tabular}


As amostras consideradas normais (Tabela 2) não apresentam valores prejudiciais de sais solúveis, nem sódio trocável. O sistema de irrigação por sulco é aplicado apenas na propriedade 3. Nas propriedades 4, 10 e 11, o sistema empregado é a microaspersão. Em todas as áreas citadas, é aplicada adubação química, apenas na propriedade 10 faz uso de adubação orgânica juntamente com os produtos químicos. O manejo ocorre através do conhecimento transmitido por gerações, exceto na propriedade 10 , que recebe assistência técnica dos estabelecimentos de comercialização de produtos agrícolas.

As características de manejo das propriedades consideradas normais diferenciam das demais com problemas de salinização. Essas propriedades apresentam: período de descanso dos solos entre um plantio e outro; e foram beneficiadas por mais tempo pelo dreno construído pela CODEVASF, principalmente no exemplo das propriedades 3 e 10. A propriedade 11 possui mais de 40 anos de uso para a agricultura irrigada (Tabela 3), mas, diferentemente das demais, nesta área nunca foi plantado arroz por inundação. Por sua vez, a propriedade 4 se destaca pelo pouco tempo de cultivo e por ter, desde o início da implantação, sistema de irrigação por microaspersão.

\section{Conclusões}

A aplicação do presente estudo concluiu que o manejo aplicado na comunidade Quilombola de Cupira vem auxiliando no desenvolvimento do processo de salinização dos solos. O plantio de arroz por inundação em décadas anteriores, o sistema de irrigação por sulco sem assistência técnica adequada e a aplicação de adubação química vem contribuindo para o acúmulo de sais nos solos que já apresentam áreas improdutivas.

A falta de sistema de drenagem e a aplicação excessiva de água e produtos químicos, sem as devidas adequações às características ambientais locais, por falta de assistência técnica e ajuda de políticas públicas aos agricultores, potencializa o problema da salinização do solo. Mais estudos precisam ser realizados para validar esta hipótese, ainda que ela esteja absolutamente compatível com estudos equivalentes realizados em outras áreas do semiárido brasileiro.

\section{Agradecimentos}

Os autores agradecem a CAPES (Coordenação de Aperfeiçoamento de Pessoal de Nível Superior) pela bolsa de mestrado cedida à primeira autora.

\section{Referências}

AGUIAR NETTO, A. O.; GOMES, C. C. S.; LINS, C. C. V.; BARROS, A. C.; CAMPECHE, L. F. S.M.; BLANCO, F. F. Características químicas e salino-sodicidade dos solos do Perímetro Irrigado Califórnia, SE, Brasil. Ciência Rural, Santa Maria, v. 37, n. 6, p.1640-1645, 2007.

BELTRÃO, B. A.; MASCARENHAS, J. C.; MIRANDA, J. L. F.; SOUZA JUNIOR, L. C.; GALVÃO, M. J.T.G.; PEREIRA, S. N. Projeto cadastro de fontes de abastecimento por água subterrânea. Diagnóstico do município de Petrolina, estado de Pernambuco. Recife: CPRM/PRODEEM, 2005.

BOHN, H.; McNEAL, B. L.; O’CONNOR, G. A. Salt-afected soils. In: Soil Chemistry. New York, Willey Interscience Publication, 1985. p. 234-261.

CASTRO, F. C.; ARAÚJO, J. F.; SANTOS, A. M. Susceptibility to soil salinization in the quilombola community of Cupira - Santa Maria da Boa Vista - Pernambuco - Brazil. CATENA, v.179, p.175-183, 2019. https://doi.org/10.1016/j.catena.2019.04.005.

CHU, S.; ZHANG, D.; WANG, D.; ZHI, Y.; ZHOU, P. Heterologous expression and biochemical characterization ofassimilatory nitrate and nitrite reductase reveals adaption andpotential of Bacillus megaterium NCT-2 in secondary salinization soil. International Journal of Biological Macromolecules, v.101, p.1019-1028, 2017. https://doi.org/10.1016/j.ijbiomac.2017.04.009.

DALIAKOPOULOS, I. N.; TSANIS, I. K.; KOUTROULIS, A.; KOURGIALAS, N. N.; VAROUCHAKIS, A. E.; KARATZAS, G. P.; RITSEMA, C. J. The threat of soil salinity: A European scale review. Science of the Total Environment, v.573, p.727-739, 2016. https://doi.org/10.1016/j.scitotenv.2016.08.177. 
EMBRAPA. Empresa Brasileira de Pesquisa Agropecuária. Seleção do Sistema de Irrigação. 1.ed. Lagoas: EMBRAPA, 2001. 18p.

EMBRAPA. Empresa Brasileira de Pesquisa Agropecuária. Manual de métodos de análises de solo. 2ed. Rio de Janeiro: EMBRAPA, 2011. 230p.

FENG, G.; ZHANG, Z.; WAN, C.; LU, P.; BAKOUR, A. Effects of saline water irrigation on soil salinity and yield of summer maize (Zea mays L.) in subsurface drainage system. Agricultural Water Management, v.193, p.205-213, 2017. https://doi.org/10.1016/j.agwat.2017.07.026.

FERREIRA, P.; SILVA, J., B., L.; RUIZ, H., A. Aspectos físicos e químicos de solos em regiões áridas e semiáridas. In: GHEYI, H. R.; DIAS, N. S.; LACERDA, C. F. (Orgs.) Manejo da salinidade na agricultura: estudos básicos e aplicados. Fortaleza: INCTSal, 2010, p. 22-41.

FILIZOLA, H. F.; GOMES, M. A. F.; SOUZA, M. D. Manual de procedimentos de coleta de amostras em áreas agrícolas para análise da qualidade ambiental: solo, água e sedimentos. EMBRAPA: Jaguariúna, 2006. 169p.

FREIRE, M.B.G.S.; MIRANDA, M.F.A.; OLIVEIRA, E.E.M.; SILVA, L.E.; PESSOA, L.G.M.; ALMEIDA, B.G. Agrupamento de solos quanto à salinidade no Perímetro Irrigado de Custódia em função do tempo. Revista Brasileira de Engenharia Agrícola e Ambiental, v.18, p.86-91, 2014.

FEITOSA, H. O.; LACERDA, C. F.; ARAÚJO, I. C. S.; FERREIRA, F. J.; CARVAlHO, C. M.; MARINHO, A. B. Chemical Soil Attributes in a Rotating System under Salinity and Nitrogen Trials. Journal of Experimental Agriculture International, v.21, p. 1-11, 2018. https://doi.org/10.9734/JEAI/2018/39321.

FREIRE, M. B. G. S.; FREIRE, F. J.; PESSOA, L. G. M.; SOUZA, E. R.; GHEYI, H. R. Salt Affected Soils in the Brazilian Semiarid and hytoremediation as a Reclamation Alternative. In: TALEISNIK, E.; LAVADO, R. S. (Orgs.) Saline and Alkaline Soils in Latin America. Springer, 2020, p.119-139. https://doi.org/10.1007/978-3-030-52592-7_6.

GONÇALVES, M. C.; MARTiNS, J. C.; RAMOS, T. B. A salinização do solo em Portugal. Causas, extensão e soluções. Revista de Ciências Agrárias, p.574-586, 2015. https://doi.org/10. 19084/RCA15140 .

GKIOUGKIS, I.; KALLIORAS, A.; PLIAKAS, F.; PECHTELIDIS, A.; DIAMANTIS, V.; DIAMANTIS, I.; ZIOGAS, A.; DAFNIS, I. Assessment of soil salinization at the eastern Nestos River Delta, N.E. Greece. CATENA, v. 128, p. 238-251, 2015. https://doi.org/10.1016/j.catena.2014.06.024.

IBGE - Instituto Brasileiro de Geografia e Estatística. IBGE Cidades. Disponível <http://www.ibge.gov.br/home/>. Acesso em: 30 de dezembro de 2017.

LEPSCH, I. F. 19 lições de Pedologia. Oficina de textos: São Paulo, 2011.

LIMA, V. L. A.; FARIAS, M. S. S.; JÚNIOR BORGES, J. C. F. Drenagem agrícola no manejo dos solos afetados por sais. In: GHEYI, H. R.; DIAS, N. S.; LACERDA, C. F. (Orgs.) Manejo da salinidade na agricultura: estudos básicos e aplicados. Fortaleza: INCTSal, 2010, p. 370-382.

MARRENJO, G. J.; PÁDUA, E. J.; SILVA, C. A.; SOARES, P. C.; ZINN, Y. L. Impactos do cultivo por longo tempo de arroz inundado em Gleissolos. Pesquisa agropecuária brasileira, v.51, n.8, p.967-977, 2016.

MATOS, A. T.; ALMEIDA NETO, O. B.; MATOS, M. P. Saturação do complexo de troca de solos oxídicos com sódio. Revista Brasileira de Engenharia Agrícola e Ambiental, v.18, n.5, p.501-506, 2014.

MEDEIROS, J. F.; NASCIMENTO, L. B.; GHEYI, H. R. Manejo do solo-água-planta em áreas afetadas por sais. In: GHEYI, H. R.; DIAS, N. S.; LACERDA, C. F. (Orgs.) Manejo da salinidade na agricultura: estudos básicos e aplicados. Fortaleza: INCTSal, 2010, p.280-302. 
MOREIRA, L. C. J.; TEIXEIRA, A. S. T.; GALVÃO, L. S.; Laboratory Salinization of Brazilian Alluvial Soils and the Spectral Effects of Gypsum. Remote Sensing, v.6, p.2647-2663, 2014. https://doi.org/10.3390/rs6042647.

MOTA, L. H. S. O.; GOMES, A. S.; VALLADARES, G. S.; MAGALHÃES, R. M. F.; LEITE, H. M. F.; SILVA, T. A. Risco de salinização das terras do baixo Acaraú (CE). Revista Brasileira Ciência Solo, v.36, p. 1203-1209, 2012.

PAN, C.; LIU, C.; ZHAO, H.; WANG, Y. Changes of soil physico-chemical properties and enzyme activities in relation to grassland salinization. European Journal of Soil Biology, v. 55, p.13-19, 2013. https://doi.org/10.1016/j.ejsobi.2012.09.009.

PEDROTTI, A.; CHAGAS, R. M.; RAMOS, V. C.; PRATA, A. P. N.; LUCAS, A. A.T.; SANTOS, P. B. Causas e consequências do processo de salinização dos solos. Revista Eletrônica em Gestão, Educação e Tecnologia Ambiental Santa Maria, v.19, n. 2, p. 1308-1324, 2015. https://doi.org/105902/2236117016544.

PENG, J.; JI, W.; MA, Z.; LI, S.; CHEN, S.; ZHOU, L.; SHI, Z. Predicting total dissolved salts and soluble ion concentrations in agricultural soils using portable visible near-infrared and mid-infrared Spectrometers. Biosystems engineering, v.152, p.94 - 103, 2016. https://doi.org/10.1016/j.biosystemseng.2016.04.015 .

RAJPUT, V. D.; MINKINA, T.; YANING, C.; SUSHKOVA, S.; CHAPLIGIN, V. A.; MANDZHIEVA, S. A review on salinity adaptation mechanism and characteristics of Populus euphratica, a boon for arid ecosystems. Acta Ecologica Sinica, v.36, p.497-503, 2016. https://doi.org/10.1016/j.chnaes.2016.08.001 .

RESENDE, R. S.; AMORIM, J. R. A.; CRUZ, M. A. S.; MENESES, T. N. Distribuição espacial e lixiviação natural de sais em solos do Perímetro Irrigado Califórnia, em Sergipe. Revista Brasileira de Engenharia Agrícola e Ambiental, v.18, (Suplemento), p.46-S52, 2014.

RICHARDS, L. A. Diagnosis and improvement of saline and alkali soils. Washington: US Department of Agriculture, 1954.

RIBEIRO, M. R. Origem e classificação dos solos afetados por sais. In: GHEYI, H. R.; DIAS, N. S.; LACERDA, C. F. (Orgs.) Manejo da salinidade na agricultura: estudos básicos e aplicados. Fortaleza: INCTSal, 2010, p.12-19.

RODRÍGUEZ-LIÉBANA, J. A.; MINGORANCE, M. D.; PEÑA, A. Thiacloprid adsorption and leaching in soil: Effect of the composition of irrigation solutions. Science of the Total Environment, v. 610-611, p.367-376, 2018. https://doi.org/10.1016/j.scitotenv.2017.08.028.

QUEIROZ, J. E.; GONÇALVES, A. C. A.; SOUTO, J. S.; FOLEGATTI, M. V. Avaliação e monitoramento da salinidade do solo. In: GHEYI, H. R.; DIAS, N. S.; LACERDA, C. F. (Orgs.) Manejo da salinidade na agricultura: estudos básicos e aplicados. Fortaleza: INCTSal, 2010, p.63-82.

SHEN, W.; NI, Y.; GAO, N.; BIAN, B.; ZHENG, S.; LIN, X.; CHU, H. Bacterial community composition is shaped by soil secondary salinization and acidification brought on by high nitrogen fertilization rates. Applied Soil Ecology, v.108, p.76-83, 2016. https://doi.org/10.1016/j.apsoil.2016.08.005 .

SILVA, P. F.; LIMA, C. J. G. S.; BARROS, A. C.; SILVA, E. M.; DUARTE, S. N. Sais fertilizantes e manejo da fertirrigação na produção de tomateiro cultivado em ambiente protegido. Revista Brasileira de Engenharia Agrícola e Ambiental, v.17, n.11, p.1173-1180, 2013.

SILVA, A. O. A fertirrigação e o processo de salinização de solos em ambiente protegido. Nativa, v.2, n.3, p.180-186, 2014.

SILVA, A. K. O.; SILVA, H. P. B. O processo de desertificação e seus impactos sobre os recursos naturais e sociais no município de Cabrobó - Pernambuco - Brasil. PRACS: Revista Eletrônica de Humanidades do Curso de Ciências Sociais da UNIFAP, v.8, n.1, p. 203-215, 2015. 
TESTEZLAF, R. Irrigação: métodos, sistemas e aplicações. Campinas: Unicamp/FEAGRI, 2017, 215 p.

USSL STAFF. United States Salinity Laboratory. Diagnosis and improvement of saline and alkali soils. Washington: U.S. Department of Agriculture, 1954.

VASCONCELOS, M. C. C. A. Salinização do solo em áreas irrigadas: Aspectos físicos e químicos. ACSA Agropecuária Científica no Semi-Árido, v.10, n. 1, p. 20-25, 2014.

VASCONCELOS, R.R.A.; BARROS, M.F.C.; SILVA, E.F.F.; GRACIANO, E.S.A.; FONTENELE, A.J.P.B.; SILVA, N.M.L. Características físicas de solos salino-sódicos do semiárido pernambucano em função de diferentes níveis de gesso. Revista Brasileira de Engenharia Agrícola e Ambiental, v.17, p.12, 1318-1325, 2013. 